\title{
Role of Toxoplasmosis in Acute Flaccid Paralysis among Children
}

\author{
Zeinab I Al-Darawany ${ }^{1}$, Taghrid M Abdallah ${ }^{2}$, Talaat Fathy ${ }^{2}$, \\ Sara Abdel-Rahman ${ }^{3}$, Ashraf Salah ${ }^{3}$, Rashad M Lasheen ${ }^{4}$ \\ ${ }_{2}^{1}$ Paediatrics Department, Faculty of Medicine, Zagazig University, Egypt \\ ${ }^{2}$ Tropical Medicine Department, Faculty of Medicine, Zagazig University, Egypt \\ ${ }^{3}$ Parasitology Department, Faculty of Medicine, Zagazig University, Egypt \\ ${ }^{4}$ Sharkiya Directorate of Health and population, Egypt
}

Corresponding Author Talaat Fathy

Mobile: 01113010250

E mail:

talaat_fathy1972@yah oo.com

Received: $5 / 10 / 2012$

Accepted after

Revision: 29/10/2012

Key words: GuillainBarré syndrome ;Acute Flaccid

Paralysis;Toxoplasma
Background and study aim: With the eradication of poliomyelitis, GuillainBarré syndrome (GBS) is the most common cause of Acute Flaccid Paralysis (AFP) in children. The present study aimed at assessment of how far Toxoplasmosis contributes to the cases of Acute Flaccid Paralysis (AFP) among children in Sharqiya governorate, Egypt. Patient and Methods: Over years from April 2010 to September 2012, one hundred children with non-polio acute flaccid paralysis were selected, after their parent written consent, out of children monitored in Sharqiya Governorate by the Project of Acute Flaccid Paralysis (AFP) Surveillance, the Ministry of Health and Population, Egypt. As they underwent treatment by appropriate therapy for AFP, anti-Toxoplasma IgM and IgG antibodies, anti-Campylobacter jejuni $\operatorname{IgM}$ and $\operatorname{IgG}$ antibodies and tumor necrosis factor alpha (TNF- $\alpha$ ) were sought quantitatively in their sera by ElISA.

\section{INTRODUCTION}

With the eradication of poliomyelitis, Guillain-Barré syndrome (GBS) is the most common cause of Acute Flaccid Paralysis (AFP) in children [1].

Guillain-Barré syndrome (GBS) is an acute disease of the peripheral nervous system of humans, characterized by ascending paralysis, conduction block with segmental demyelination of the nerves, macrophage and lymphocytic infiltration of the nerves, and elevated protein with no cells or very few cells in the cerebrospinal fluid [2]. GBS has been shown to be associated with viral or bacterial infections, including
Results:Anti-Toxoplasma $\operatorname{IgM}$ and $\operatorname{IgG}$ were respectively detected among 3 (3\%) and $42(42 \%)$ of them. Anticampylobacter IgM and IgG were respectively detected among $25(25 \%)$ and $54(54 \%)$ of them. TNF- $\alpha$ absorbance values were $0.95 \pm 0.35$ among 3 patients with symptomatic acute toxoplasmosis (positive $\operatorname{IgM}$ and $\operatorname{IgG}$ ), $0.22 \quad \pm 0.11$ among 39 patients with chronic toxoplasmosis (with positive anti Toxoplasma IgG only), and $0.21 \pm 0.12$ among patients without toxoplasmosis. The 3 cases of acute flaccid paralysis due to acute toxoplasmosis did not respond to the ordinary treatment of AFP treatment; but dramatically responded to Sulfadiazine and Pyrimethamine. Conclusion: These results may make the study hypothesize that Toxoplasma may exert its pathogenic effect on nerve myelin directly via TNF- $\alpha$. Thus approaching Acute Flaccid Paralysis, higher index of suspicion is needed so as to do not miss cases with toxoplasmic etiology.

Campylobacter jejuni [3,4], Borrelia burgdorferi [5], Brucella melitensis [6], or infection with the protozoan parasite,Toxoplasma gondii $[7,8]$,or following vaccinations, including rabies [9] and swine influenza [10].

The present study aimed at assessment of how far Toxoplasmosis contributes to the cases of Acute Flaccid Paralysis (AFP) among children in Sharqiya governorate, Egypt.

\section{PATIENTS AND METHODS}

This study was conducted during the period between April 2010 and September 2012 at the Departments of 
Pediatrics, Tropical Medicine, Microbiology and Parasitology, Faculty of Medicine, Zagazig University. The study was carried out, after written and oral consent from the parents of 100 cases of non-polio acute flaccid paralysis proved in time to be copro-negative for Polioviruses by stool cultivation that was made by the Project of Acute Flaccid Paralysis surveillance of the Ministry of Health and Population, Egypt.

The patients were subjected in time to the following: thorough history taking and clinical examination and blood sample collection so as to separate and store sera at $2-8{ }^{\circ} \mathrm{C}$ to seek antiToxoplasma IgM and IgG antibodies, antiCampylobacter jejuni IgM and $\mathrm{IgG}$ antibodies and Tumour necrosis factor- $\alpha$.

According to anti-Toxoplasma seropositivity; the cases were classified into 3 groups of AFP:

1. Acute flaccid paralysis with acute toxoplasmosis on basis of anti-Toxoplasma IgM seropositivity.

2. Acute flaccid paralysis with chronic toxoplasmosis on basis of anti-Toxoplasma IgM seronegativity and IgG seropositivity.

3. Acute flaccid paralysis without toxoplasmosis on basis of negative antiToxoplasma serology.

Management of the cases was carried out by: corticosteroids, intravenous human immunoglobulin (IVIG) or by plasmapheresis if recommended. Specific anti-Toxoplasma therapy was applied to the cases with Toxoplasma seropositivity after failure of afore- mentioned measures. Pyrimethamine was given as loading dose: $2 \mathrm{mg} / \mathrm{kg} / 24$ hours for the first 2 days of treatment and Maintenance dose of $1 \mathrm{mg} / \mathrm{kg} / 24$ hours altogether with Folinic acid: $20 \mathrm{mg}$ three times a week or even daily depending on the leukocyte count [11].

\section{Case definition:}

The diagnosis of acute toxoplasmosis was established by the presence of a serum Toxoplasma IgM titre of $1 / 8$ by ELIS A together with the clinical triad of fever ( chills or documented fever), headache and lymphadenopathy, in addition to history of contact with cats $[12,13]$.

The cases of AFP who met the following criteria were regarded to be induced by acute toxoplasmosis: Anti-Toxoplasma IgM seropositivity, significantly high level of Tumour necrosis factor (TNF- $\alpha$ ), anti-Campylobacter jejuni IgM seronegativity, and good response to anti-Toxoplasma treatment.

- Qualitative Serotesting for antiToxoplasma IgM and IgG antibodies According to Montoya and Rosso, [14]. Kits of the Onsite Toxo IgG/ IgM Rapid Test- Cassette (Serum/ plasma) Catalog no. R0233C were obtained from CTK Biotech, Inc., 6748 Nancy Ridge Drive. San Diego, CA 92121, USA. This Rapid test depends on a lateral flow chromatographic immunoassay, for the simultaneous detection and differentiation of $\mathrm{IgG}$ and IgM anti-Toxoplasma Gondii ( $\mathrm{T}$. gondii) in human serum or plasma. The reactive specimens with the onsite toxo IgG/IgM Rapid test were confirmed with the quantitative ELISA test. If only the control (C) band is present, the absence of any burgundy color in both $\mathrm{T}$ bands (T1 (IgM) and T2 (IgG)) indicates that no anti T. gondii antibodies are detected in the specimen. The result is negative. In addition to the presence of $\mathrm{C}$ band, if only $\mathrm{T} 2$ band is developed the test indicates for the presence of $\mathrm{IgG}$ anti- $T$. gondii in the specimen, the result is IgG positive. If both $\mathrm{T} 1$ and $\mathrm{T} 2$ bands are developed, the test indicated the presence of both $\mathrm{IgG}$ and IgM anti-T. gondii in the specimen.

- Quantitatve IgM anti Toxoplasma Serotesting by Enzyme - linked Immunosorbent Assay (ELISA) according to Johnson and Holliman [15]. Equipment and reagents were purchased from Organon Technica. Briefly, 100

$\mu l$ of PBST/BSA was added into two wells of each plate to function as the antigen/conjugate and substrate controls. $100 \mu$ of each test serum, one negative, and one positive control sera diluted 1/1000 was mixed well and aliquoted into wells of the micro titration plates pre-coated with human $\mu$ heavy chain of IgM. Then incubated for one hour and washed, The Toxoplasma antigen/conjugate were dispensed \& mixed in each well. After being covered and incubated at $37{ }^{\circ} \mathrm{C}$ for one hour, the substrate solution $(100$ $\mathrm{mg} / 10 \mathrm{ml}$ DMSO) was added immediately and rapidly to every well. Then the reaction was stopped by adding $25 \mu \mathrm{l}$ of one $\mathrm{M} \mathrm{H}_{2} \mathrm{SO}_{4}$ to each well. The absorbance (optical density) was measured at a wavelength of $450 \mathrm{~mm}$ blanking the plate against the substrate control well using a spectrophotometer. Absorbance value of $\leq 0.4$ was considered negative. Absorbance $\geq 0.5$ was positive. 
- Detection of Campylobacter jejuni IgM and IgG antibodies by the commercially available (ELISA recomWell Campylobacter) from Microgen, Poland according Schmidt-Ott et al[16]. Kits of the Human Campylobacter Jejuni PEB1 ELISA Kit Catalog number: CDN-E0568, were obtained from Creative Diagnostics, CD Bio Sciences, Inc., 45-16 Ramsey Road Shirley, NY11967 USA. Strip plate with micro wells coated with $100 \mu$ l of rabbit antihuman $\mu$ or $\gamma$ chain, Creative diagnostics were washed prior to use thrice with PBS/T. Well A1 was left empty (blank). $100 \mu \mathrm{l}$ of $1 / 50$ dilution (2\% casein with PBS) of a Campylobacter jejuni IgM or $1 / 100$ IgG serum negative and positive control sera were dispensed into two coated wells. $100 \mu 1$ of patient's serum (with 1/50 dilution in IgM assay and $1 / 100$ in IgG assay) were dispensed into the other coated wells. The wells were incubated and washed. $100 \mu \mathrm{l}$ of sonicated Campylobacter jejuni organism (Reactive Diagnostics) were dispensed into the wells. After second incubation and coverage, $100 \mu \mathrm{l}$ of peroxidase-conjugated anti - Campylobacter jejuni; Reactive diagnostics were dispensed into each well. Then $100 \mu \mathrm{l}$ of one $\mathrm{M} \mathrm{H}_{2} \mathrm{SO}_{4}$ were dispensed into each well to stop in reaction. The absorbance value of each well was read in an ElISA strip reader at 450 $\mathrm{nm}$. Values $\geq 0.2$ were considered positive for IgM assay and values $\geq 0.4$ were considered positive for IgG assay according to the manufacturer.

- Quantitative ELISA for Estimation of Tumor Necrosis Factor Alpha (TNF-a)
According to Thomas [17]. The number of eight well strips needed for the assay were determined and inserted in the frame. Fifty $\mu \mathrm{ls}$ of the incubation buffer were added to all wells and the well reserved for chromogen blank were left empty. One hundred $\mu \mathrm{ls}$ of the standard diluents buffer were added to the zero standard wells and the well reserved for chromogen blank were left empty. One hundred $\mu$ ls of standards were added to the appropriate micro titer wells and fifty $\mu$ of standard diluents buffer were added to each well followed by fifty $\mu \mathrm{l}$ of each test sample. Fifty $\mu \mathrm{l}$ of biotinylated anti- TNF- $\alpha$ (Biotin conjugate) solution were put in each well except the chromogen blank. Then, the plate was incubated and washed. One hundred $\mu 1$ of StreptavidinHRP working solution were added to each well except the chromogen blank. After second incubation and washing, one hundred $\mu \mathrm{l}$ of Stabilized Chromogen were added to each well and the liquid in the wells started to become blue. After 30 minutes, one hundred $\mu 1$ of Stop solution were added to each well until the solution in the wells was changed from blue to yellow. Then the absorbance of each well was read at $450 \mathrm{~nm}$ having blanked the plate reader against a chromgen blank composed of $100 \mu \mathrm{l}$ each of Stabilized Chromogen and Stop Solution then the plate was read within 2 hours after adding stop solution.

Results were tabulated and statistical inference on difference between means, were made by $\mathrm{t}$ student test and on difference between proportions by $\mathrm{Z}$ test.

\section{RESULTS}

Table (1): Age of AFP cases

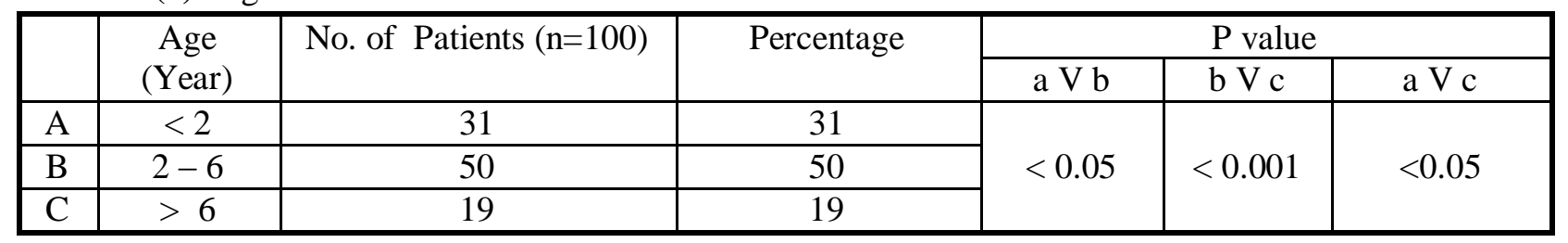

Table (2): Male/Female ratio in all cases

\begin{tabular}{|c|c|c|c|}
\hline Sex & No. of Patients $(\mathrm{n}=100)$ & Percentage & P value \\
\hline Male & 57 & 57 & \multirow{2}{*}{$>0.05$} \\
\hline Female & 43 & 43 & \\
\hline
\end{tabular}

Table (3): Anti-Toxoplasma IgM \& IgG seropositivity among AFP cases

\begin{tabular}{|c|c|c|c|c|}
\hline & No. examined patients & Number of Positive Cases & $\%$ & P value \\
\hline $\operatorname{Ig~M}$ & 100 & 3 & 3 & $<0.01$ \\
\hline $\operatorname{IgG}$ & 100 & 42 & 42 & \\
\hline
\end{tabular}

Al-Darawany et al., Afro-Egypt J Infect Endem Dis 2012; 2(4): 155-161

www.mis.zu.edu.eg/ajied/home.aspx 
Table (4): The Positivity as referred to positive control and level of (TNF- $\alpha$ ) Among Cases

\begin{tabular}{|l|l|l|l|l|l|l|}
\hline & & No. examined & Seropositive & \multirow{2}{*}{$\%$} & \multicolumn{2}{|l|}{ Optical density } \\
\cline { 6 - 7 } & & & & & Mean & SD \\
\hline A & acute toxoplasmosis & 3 & 3 & $100^{*}$ & 0.95 & $0.035^{\square}$ \\
\hline B & Chronic toxoplasmosis & 39 & 1 & $2.55^{* *}$ & 0.22 & $0.11^{\square \square}$ \\
\hline C & Without toxoplasmosis & 58 & 1 & 1.77 & 0.21 & 0.12 \\
\hline
\end{tabular}

Table (5): Clinical picture of toxoplasma related manifestations among the cases

\begin{tabular}{|ll|l|l|}
\hline \multicolumn{2}{|c|}{ Clinical Picture } & No. Patients $(\mathrm{n}=100)$ & Percentage \\
\hline - & Lymphadenopathy & 3 & $3 \%$ \\
\hline - & Retinochoroiditis & 2 & $2 \%$ \\
\hline - & Pulmonary & 0 & 0 \\
\hline - & Hepatomegaly & 0 & 0 \\
\hline & Splenomegaly & 0 & 0 \\
\hline
\end{tabular}

Table (6): Prevalence of: anti- Campylobacter jejuni IgG seropositivity among AFP cases

\begin{tabular}{|c|c|c|c|c|}
\hline & & No. examined & No. IgG seropositive & $\%$ \\
\hline A & Acute toxoplasmosis & 3 & 1 & $33.3^{\square}$ \\
\hline B & Chronic toxoplasmosis & 39 & 20 & $51.28^{\square}$ \\
\hline C & Without toxoplasmosis & 58 & 33 & 56.89 \\
\hline
\end{tabular}

${ }^{\square} \mathrm{P}$ value versus $\mathrm{b} \& \mathrm{c}<0.05-{ }^{\square} \mathrm{P}$ value versus $\mathrm{c}>0.05$

Table (7): Prevalence of anti-Campylobacter jejuni IgM seropositivity among AFP cases

\begin{tabular}{|c|c|c|c|c|}
\hline & & No. examined & No. IgM seropositive & $\%$ \\
\hline A & Acute toxoplasmosis & 3 & 0 & $0^{*}$ \\
\hline B & Chronic toxoplasmosis & 39 & 8 & $20.51^{* *}$ \\
\hline C & Without toxoplasmosis & 58 & 17 & 29.31 \\
\hline
\end{tabular}

$* \mathrm{P}$ value versus $\mathrm{b} \& \mathrm{c}<0.001-* * \mathrm{P}$ value versus $\mathrm{c}>0.05$

\section{DISCUSSION}

The incidence of AFP was 2.3-2.39/100.000 among children aged less than 15 years in Sharkiya governorate from April 2010 to September 2012 by the project of acute flaccid paralysis surveillance, the Ministry of Health and Population. Several infections as well as immunizations have been known to precede or to be associated with Guillain-Barré syndrome (GBS) [1]. Only a few cases of acute polyradiculoneuritis have been reported in patients with increasing levels of immunoglobulin $\mathrm{G}$ ( $\mathrm{IgG}$ ) and I g M antibodies directed against Toxoplasma gondii [18]. Recently, it has been documented that AFP in some dogs, like GBS in some humans, may be triggered by Toxoplasma gondii infection [19].

The present study showed that the prevalence of chronic toxoplasmosis was $42 \%$ among the study population; the prevalence of symptomatic acute toxoplasmosis was limited to $3 \%$. These prevalence rates, more or less agree with McLeod and Remington who reported that several studies made on random populations have detected significant antibody titers that ranged $50-80 \%$ of residents in some localities and less than $5 \%$ in others. These authors added 
that Toxoplasma infection is one of the most common latent infections of humans throughout the world [11].

This study revealed that the 3 cases AFP were positive for Acute Toxoplasmosis and all the 3 cases were with significant high levels of TNF- $\alpha$. This finding may suggest that Toxoplasma exerts its pathogenic effect on the nerves via the increased production of TNF- $\alpha$ thus leading to induction of acute flaccid paralysis. The role of toxoplasmosis in production of tumor necrosis factor-alpha (TNF $\alpha$ ) has been discussed in many reports [20]. Toxoplasma tachyzoites stimulate macrophages to produce interleukin (IL-12) [21]. IL-12, in turn activates natural killer (NK) cells and $\mathrm{T}$ cells to produce interferon- (IFN-) and it is this early produced IFN- that is crucial for resistance [22,23].

IFN- and tumor necrosis factor (TNF) a ct synergistically to mediate killing of tachyzoites by macrophages. The combination of these two cytokines results in greatly enhanced production of free radicals and nitric oxide (NO) both of which can affect parasite killing [22, 24]. In toxoplasmosis, various cell types including macrophages, microglia, neutrophils, $\mathrm{T}$ cells and dendritic cells produce TNF. Production of TNF is induced by IFN- $\gamma$ in infected cells and the latter cytokine and its receptor have a pivotal role in the control of $T$. gondii in mice [25].

The role of tumor necrosis factor-alpha (TNF $\alpha$ ) in acute flaccid paralysis has been stated by many authors; Trojaborg reported that: Other factors of importance in the pathogenesis of GBS: T lymphocytes and macrophages secrete TNF $\alpha$, which has a toxic effect on myelin, Schwann cells and endothelial cells [26]. There is a close relation between the amount of circulating tumor necrosis factor- $\alpha$ in serum and prolonged distal latency, slow motor conduction velocity and reduced compound muscle action potential (CMAP) amplitude in GBS patients suggesting a role for TNF- $\alpha$ in the pathogenesis of peripheral nerve demyelination. Similar correlations were not observed for serum levels of interleukine-1 or soluble interleukine-2 receptors [27]. Recently, $\mathrm{Wu}$ et al., found a significant association between TNF- $\alpha$ and risk of the GBS in Asian population [28]. On the other hand, Prasad et al., stated that TNF polymorphisms may increase susceptibility to axonal GBS subtypes [29]; however, the role of
TNF in GBS remains unclear and wants further investigation.

As far as it has been reviewed; the present study in Egypt may be the first to accuse Toxoplasma as a one of the causative agents of AFP in a survey study. The present study recorded that cases of acute flaccid paralysis due to toxoplasmosis, do not respond to the ordinary treatment of AFP treatment. This finding was supported by Bossi et al. [8], who reported that the patient's condition improved with pyrimethamine $(50 \mathrm{mg} /$ day), sulfadiazine (4 $\mathrm{g} /$ day), and folinic acid (25 $\mathrm{mg} /$ day). Fever disappeared within 5 days, lymph node disorders within 10 days, and neurologic disorders and retinochoroiditis within 15 days. The treatment was stopped after 6 weeks. Ten months later, the patients became fully recovered. They reported also that a poor host adaptation to the uncommon highly virulent tropical strains of $T$. gondii can explain these unusual clinical presentations. They attributed the occurrence of Guillain-Barré syndrome among immune competent patient, to infection with a new strain of $T$. gondii. This strain was highly virulent, as confirmed by the rapid death of the mice (within 3 days). Moreover, this strain was not affected by a 10day treatment with spiramycin (which is ineffective in toxoplasmosis with central nervous system symptoms), and parasitemia remained after this therapy. Parallel poor host adaptation may have occurred with the 3 cases of the present study

The study assessed also the role of Campylobacter jejuni as causative agent of AFP. The study recorded that Campylobacter jejuni comes as the most common cause of GuillainBarré syndrome; our study revealed that: 25 AFP cases $(25 \%)$ were positive for antiCampylobacter jejuni IgM while 54 AFP cases (54\%) were positive for anti- Campylobacter jejuni $\operatorname{IgG}$. Kalra et al., in an Indian case-control study reported that $27.7 \%$ of childhood GBS cases were associated with $C$ jejuni infection [30]. Hughes and Rees (1997) stated that among infectious agents, Campylobacter jejuni is the most frequently identified cause of Guillain- Barré syndrome [31].

\section{CONCLUSION}

Approaching Acute Flaccid Paralysis, higher index of suspicion is needed so as to do not miss 
Cases with toxoplasmic etiology. Toxoplasmic Acute Flaccid Paralysis needs specific treatment in the form of pyrimethamine and sulfadiazine and there is no response to the other forms of treatment. The study hypothesize that Toxoplasma may exert its pathogenic effect on nerve myelin directly via TNF- $\alpha$. Treatment with specific anti-Toxoplasma chemotherapy may shorten the course of recovery and improve the prognosis of acute flaccid paralysis.

\section{Funding: None.}

Conflicts of interest: The authors declare that there is no conflict of interest.

Ethical approval: The protocol of the study was approved by the committee of Faculty of Medicine , Zagazig University. Where the procedures followed were in accordance with the ethical standards of the responsible committee on human experimentation (institutional or regional) and with the Helsinki Declaration of 1964. Informed consents were obtained from all patients.

\section{REFERENCES}

1. Hughes RA, Cornblath DR. Guillain-Barre syndrome. Lancet 2005; 366:1653-66.

2. Constantinescu CS, Hilliard B, Fujioka T, Bbopale MK, Calida D, Rostami AM. Pathogenesis of neuroimmunologic diseaseexperimental models.Immunol Res1998; 17(1\&2):217-27.

3. Rokosz N, Rastawicki W, Jagielski M, Hetkowska-Abramczyk Z. Detection of antibodies to Campylobacter jejuni in pediatrics patients with Gullain-Barré syndrome using different antigen preparations. Med Dosw Mikrobiol 2011; 63(3): 255-61. Polish

4. Barzegar M, Alizadeh A, Toopchizadeh V, Dastgiri S, Majidi J. Association of Campylobacter jejuni infection and GuillainBarré syndrome: a cohort study in the northwest of Iran. Turk J Pediatr 2008; 50(5):443-8.

5. Sigal LH, Tatum AH. Lyme disease patients' serum contains IgM antibodies to Borrelia burgdorferi that cross-react with neuronal antigens. Neurology 1988; 38(9):1439-42.
6. Babamahmoodi F, Babamahmoodi A. Brucellosis, presenting with guillain-barré syndrome. J Glob Infect Dis 2011; 3(4):3902.

7. Pascual JM, Redón J, Villoslada C, Vila B. Guillain-Barré syndrome after acute Toxoplasma infection. Med Clin (Barc) 1984; 83(8):351-2.

8. Bossi P, Caumes E, Paris L, Darde ML, Bricaire F. Toxoplasma gondii-associated Guillain-Barre syndrome in an immunocompetent patient. $J$ Clin Microbiol 1998; (36):3724-5.

9. Hemachudha T, Griffin DE, Chen WW, Johnson RT. Immunologic studies of rabies vaccination-induced Guillain- Barré syndrome. Neurology1988; 47:668-673.

10. Greene SK, Rett M, Weintraub ES, Li L, Yin $\mathrm{R}$, Amato AA, et al. Risk of confirmed Guillain-Barre syndrome following receipt of monovalent inactivated influenza A (H1N1) and seasonal influenza vaccines in the Vaccine Safety Datalink Project, 20092010. Am J Epidemiol 2012 ; 175(11):11009.

11. McLeod R, Remington JS. Toxoplasmosis in Nelson textbook of pediatrics 19th ed. Philadelphia, W.B. Saunders 2008; P.1144:1154.

12. Teutsch S M, Juranek, D D, Sulzer A, Dubey J P, Sikes R. K. Epidemic toxoplasmosis associated with infected cats. N. Engl.J. Med 1979; 300:695-699.

13. McLeod $\mathrm{R}$ and Remington JS . Toxoplasmosis. Chapter 157 in HARRISON'S Principles of INTERNAL MEDICINE. 11th edition" Published in United States by McGrawHill Company, Inc 1987; N.Y P.815.

14. Montoya JG, Rosso F. Diagnosis and management of toxoplasmosis. Clin Perinatol 2005; 32 (3): 705-26.

15. Johnson JD, Holliman RE. Toxoplasmosis in "medical Parasitology a practical approach" Published in United States by Oxford University Press Inc.2002; N.Y.P. 33:59. 
16. Schmidt-Ott R, Bass F, Scholz C, Wener C, Grob $\mathrm{U}$. Improved Serodiagnosis of Campylobacter jejuni infections using recombinant antigens. $J$ Med Microbiol 2005 ; 54,761-767.

17. Thomas A W. The Cytokine Handbook, 2nd Ed. Academic Press Ltd, London 1994; pp. 57 - 75.

18. Dano P, Le Guyader J, Caron RP. (Acute polyradiculoneuritis and toxoplasmosis), Rev Neurol (Paris) 1985; 141(11):743-5.

19. Holt N, Murray M, Cuddon PA, Lappin MR. Seroprevalence of various infectious agents in dogs with suspected acute canine polyradiculoneuritis. $\mathrm{J}$ Vet Intern Med 2011; 25:261-266.

20. Gazzinelli RT, Hieny S, Wynn TA, Wolf S, Sher A. Interleukin-12 is required for $\mathrm{T}$ lymphocyte independent induction of interferon gamma by an intracellular parasite and induces resistance in T Cell-deficient hosts. Proc Natl Acad Sci USA 1993; 90 (13) 6115-19.

21. Sher A, Reis e Sousa C. Ignition of the type I response to intracellular infection by dendritic cell derived interleukin-12. Eur Cytokine Netw 1988; 9 (3suppl): 65-68.

22. Sibley LD, Adams LP, Fukutomi Y, Krahenbuhl JL. Tumour necrosis factoralpha triggers antitoxoplasmal activity by IFN-gamma primed macrophages. $J$ Immunol 1991; 147(7): 2340-2345.

23. Daubener W, Remscheid C, Nockemann S, Pilz K, Seghrouchi S, Mackenzie C, et al. Antiparasite effector mechanism in human brain tumour cells: role of interferon- gamma and tumour necrosis factor- alpha. Eur J Immunol 1996; 26 (2): 487-492.

24. Sher A, Oswald IP, Hieny S, Gazzinelli RT. Toxoplasma gondii induces a $\mathrm{T}$ independent IFN-gamma response in natural killer cells that requires both
Adherantaccessory cells and tumour necrosis factor a $1 \mathrm{pha}$. J Immunol 1993;150 (9): 3982-3989.

25. Suzuki Y, Kang H, Parmley S, Lim S, Park D. Induction of tumor $n$ ecros is factor- $\alpha$ and inducible nitric oxide synthase fails to prevent toxoplasmic encephalitis in the absence of interferon- $\gamma$ in genetically resistant $\mathrm{BALB} / \mathrm{c}$ mice. Microbes Infect 2000; 2 (5): 455-462.

26. Trojaborg W. Acute and chronic neuropathies: new aspects of GuillainBarre'syndrome and chronic inflammatory demyelinating polyneuropathy, an overview and an update. Electroencephalography and clinical Neurophysiology 1998; 107 (5): 303-316.

27. Sharief MK, Ingram DA, Swash M. Circulating tumor necrosis factor-a correlates with electrodiagnostic abnormalities in Guillain- Barre' syndrome. Ann. Neurol 1997 ; 42(1):68-73.

28. Wu LY, Zhou Y, Qin C, Hu BL. The effect of TNF-alpha, Fc $\gamma \mathrm{R}$ and CD1 polymorphisms on Guillain-Barré syndrome risk: evidences from a meta-analysis. $J$ Neuroimmunol 2012; 243(1-2):18-24.

29. Prasad KN, Nyati KK, Verma A, Rizwan A, Paliwal VK. Tumor necrosis factor-alpha polymorphisms and expression in Guillain-Barré syndrome. Hum Immunol 2010; 71(9):905-910.

30. Kalra V, Chaudhry R, Dua T, Dhawan B, Sahu JK, Mridula B. Association of Campylobacter jejuni infection with childhood Guillain-Barré syndrome: a case-control study. J Child Neurol 2009 ; 24(6):664-8.

31. Hughes RAC, Rees JH. Clinical and epidemiological features of Guillain-Barré Syndrome. J Infect Dis1997; 176 (Suppl 2): S92-S98. 